\title{
The Prevalence of Impacted Maxillary Canines in a Palestinian Population: A Retrospective Study
}

\author{
Naji Arandi1 ${ }^{*}$, Tarek Rabi' ${ }^{2}$, Shockry Mustafa ${ }^{1}$ \\ ${ }^{1}$ Faculty of Dentistry, The Arab American University, Jenin, Palestine \\ ${ }^{2}$ Faculty of Dentistry, Al-Quds University, Jerusalem, Palestine \\ Email: ${ }^{*}$ Arandi@gmail.com
}

How to cite this paper: Arandi, N., Rabi, T. and Mustafa, S. (2017) The Prevalence of Impacted Maxillary Canines in a Palestinian Population: A Retrospective Study. Open Journal of Stomatology, 7, 283-290. https://doi.org/10.4236/ojst.2017.75022

Received: April 8, 2017

Accepted: May 21, 2017

Published: May 24, 2017

Copyright (c) 2017 by authors and Scientific Research Publishing Inc. This work is licensed under the Creative Commons Attribution International License (CC BY 4.0).

http://creativecommons.org/licenses/by/4.0/

\section{(c) (i) Open Access}

\begin{abstract}
Objective: This study aims to estimate the prevalence of impacted maxillary canines using panoramic radiographs. Methods: A sample of 1321 panoramic radiographs were retrospectively examined for the presence of impacted maxillary canines. The radiographs were obtained from the records of a private dental clinic from the year 2009 till 2016. Results: The prevalence of impacted canines among the examined population $(n=1321)$ was found to be $1.8 \%$. There was a significant association between gender and canine impaction $(\mathrm{P}<$ 0.05), indicating that in the study population, the females had higher prevalence of canine impaction than males. Unilateral impaction accounted for $79 \%$ of the cases that showed at least one impacted maxillary canine while the bilateral impaction of the maxillary canines accounted for $20 \%$ of 24 cases that had at least one impacted maxillary canine. The results reveal significantly $(\mathrm{P}<$ $0.05)$ higher unilateral canine impaction compared to bilateral impaction. Fifty eight percent of the unilateral cases were on the right side while $42 \%$ were on the left side. No significant $(\mathrm{P}>0.05)$ difference in the prevalence of right or left canine impaction was found. Conclusion: The prevalence of impacted maxillary canines $(1.8 \%)$ in this study was within the range reported among other populations.
\end{abstract}

\section{Keywords}

Impacted Teeth, Maxillary Canines, Retrospective, Prevalence

\section{Introduction}

The canine plays an important role to the dentofacial aesthetics and function; maxillary canines are essential for the canine guidance of mandibular movement and their presence contributes to the canine eminence that supports alar base 
and upper lip which in turn promotes for facial aesthetics and esthetic smiles [1].

Tooth impaction is a problem commonly encountered in dental practice [2]

[3] [4]. The term "Impacted" is used for those teeth with a delayed eruption time or that are not expected to erupt completely based on clinical and radiographic assessment [5]. Impacted maxillary canines is a frequently encountered clinical problem that compromises esthetics and function. Effective management of impacted canines is still a challenge for the general dentists their treatment is challenging and requires an interdisciplinary approach.

Impacted canines are defined as those teeth that do not erupt within 6 months of their complete root formation or when they are not present in the arch during the eruption phase [2] [6]. Maxillary canine impaction might occur unilaterally or bilaterally and more frequently in females than males. The permanent maxillary canine is reported as the second most frequently impacted tooth after third molars [7] and by other studies as the most prevalent impacted tooth [8]. This is attributed to the fact that maxillary canines are last teeth to develop and they have to travel a long path before coming into the occlusion. During this path of eruption the chances of mechanical obstruction and displacement are high [4].

The factors associated with the etiology of canine impaction can be classified into generalized, localized [2] [6]. The generalized causes include endocrine deficiencies, febrile diseases, abnormal muscle pressure, vitamin D deficiency and radiation. The localized factors may be a result of one or a combination of the following: tooth size-arch length discrepancies, prolonged retention or early loss of the deciduous canine, abnormal position of the tooth bud, the presence of an alveolar cleft, ankylosis, cystic or neoplastic formation, dilacerations of the root, agenesis of the lateral incisor, iatrogenic origin and idiopathic condition with no apparent cause [4] [6].

Many studies evaluated the prevalence of impacted canines among various populations and reported vast differences in their findings [1] [9] [10] [11] [12]. This study aimed to establish the frequency of impaction in order to acquire prevalence in the general population of the city of Nablus which would help to develop a better understanding of impacted canines in Palestine.

\section{Materials and Methods}

A retrospective, descriptive, cross-sectional study of 1321 digital panoramic radiographs was conducted. The radiographs were obtained from the records of a private dental clinic from the year 2009 till 2016. These radiographs were examined to reveal any evidence of impacted maxillary canines. The inclusion criteria involved radiographs of patients that were 15 years of age and above as by this time all the permanent teeth would be erupted. The exclusion criteria was the presence of one or more of the following conditions; a history of orthodontic treatment, permanent maxillary canine extraction, hereditary disease or syndromes and radiographs of poor quality. The radiographs were examined by two experienced examiners in order to detect impacted maxillary canines. Data were processed and analyzed using IBM SPSS Statistics V. 22 (IBM Corp. Released 
2013. IBM SPSS Statistics for Windows, Version 22.0. Armonk, NY: IBM Corp.). The chi square test was used to reveal any differences in the distribution of impacted canines when stratified by gender, location (left or right), and being unilateral or bilateral. A p-value of $<0.05$ was considered statistically significant.

\section{Results}

Of the 1321 patients, 775 were males (58.6\%) and 546 were females $(41.3 \%)$ [Table 1]; the mean age was 32.6 years, ranging from 15 to 67 years. A total of 24 cases with at least one impacted maxillary canine were found, 17 (70.9\%) were in females and 7 (29.1\%) were in males. The prevalence of impacted canines in males was $0.9 \%$ and in females was $3.1 \%$. Chi-square test reveals a significant association between gender and canine impaction $(\mathrm{P}<0.05)$, indicating that $\mathrm{fe}$ males had higher prevalence of canine impaction than males [Table 2]. The prevalence for maxillary impacted canines in all the cases was $1.8 \%$ [Table 2]. Eight cases (41\%) of the cases that had unilateral impaction were on the left side of the maxillary arch, whereas 11 cases (58\%) were on the right side. Non-parametric chi-square test reveals no significant $(P>0.05)$ difference in the prevalence of right or left canine impaction [Table 3]. Fisher's exact test of association reveals no significant association between gender and canine impaction side $(\mathrm{P}>$ 0.05 ) [Table 4]. Bilateral impaction occurred in $21 \%$ of the patients, being less

Table 1. Gender distribution of the sample size.

\begin{tabular}{ccc}
\hline Gender & n. & $\%$ \\
\hline Male & 775 & 58.6 \\
Female & 546 & 41.3 \\
Total & 1321 & 100 \\
\hline
\end{tabular}

Table 2. Association between impaction and gender.

\begin{tabular}{ccccc}
\hline & Normal & Impacted & \multicolumn{2}{c}{ Total } \\
\hline Gender & $\mathrm{n}(\%)$ & $(\mathrm{n}) \%$ & $\mathrm{n}(\%)$ & P-value \\
\hline Male & 768 & $7(0.9)$ & $575(100)$ & 0.003 \\
Female & 529 & $17(3.1)$ & $1321(100)$ & \\
Total & 1297 & $24(1.8)$ & $100)$ & \\
\hline
\end{tabular}

${ }^{1}$ Percentage of impacted teeth reported in this table is equivalent to prevalence. ${ }^{2} \mathrm{Chi}$-square test reveals a significant association between gender and canine impaction $(\mathrm{P}<0.05)$, indicating that in the study population, the females had higher prevalence of canine impaction than males.

Table 3. Prevalence of right and left impacted canines.

\begin{tabular}{ccc}
\hline & $\mathrm{n}($ Prevalence \%) & P-value \\
\hline Right & $11(0.8)$ & 0.491 \\
Left & $8(0.6)$ & \\
Total & $19(1.4)$ & \\
\hline
\end{tabular}

${ }^{1}$ Non-parametric chi-square test reveals No significant $(\mathrm{P}>0.05)$ difference in the prevalence of right or left canine impaction. 
common than the unilateral impactions, which accounted for $79 \%$ of the total cases that had at least one impacted maxillary canine. Non-parametric chi-square test reveals significant $(\mathrm{P}<0.05)$ higher unilateral canine impaction compared to bilateral impaction [Table 5].

\section{Discussion}

Various studies assessed the prevalence of impacted teeth among different study populations [13]. The present study assessed the prevalence of impacted maxillary canines without considering impaction of other teeth [14] [15] [16]. Maxillary canines impactions are reported more common than mandibular impactions [8] [17] [18]. The prevalence of maxillary canine impaction in our study was $1.8 \%$ which falls within the range $1.2 \%$ to $8.4 \%$ reported by other studies. In a study by Sajnani and King, [19] 26,039 southern Chinese children and adolescents were investigated for impacted maxillary canines $533(2.1 \%)$ presented with at least one impacted maxillary canine. Patil et al., [11] investigated the impaction of maxillary canines in 4133 patients in west India and reported a prevalence of $2.78 \%$ to have at least one impacted maxillary canine. Sharmila [16] studied 406 digital panoramic $x$-rays and found the incidence of impacted canines to be 4.19\% among the population from south India. Sandeepa et al., [20] studied the panoramic radiographs of 1050 patients in an Indian population and reported 31 patients $(2.95 \%)$ with at least one impacted maxillary canine. Kifayatuallah et al., [14] reported that out of 500 Pakistani patients examined 20 (4\%) had maxillary canine impaction. Alif et al., 2011 [15] investigated 580 panoramic radiographs of Bangladeshi patients and found that impacted maxillary canines were present in only 7 (1.2\%) radiographs. A study done in Greece found that the North Greek population had maxillary canine impaction incidence of $8.4 \%$ [13].

Table 4. Association between impaction side and gender.

\begin{tabular}{cccccc}
\hline & Right & Left & Bilateral & \multicolumn{2}{c}{ Total } \\
\hline Gender & $\mathrm{n}(\%)$ & $(\mathrm{n}) \%$ & $(\mathrm{n}) \%$ & $\mathrm{n}(\%)$ & P-value \\
\hline Male & $4(57.1)$ & $1(14.3)$ & $2(28.6)$ & $7(100)$ & 0.502 \\
Female & $7(41.2)$ & $7(41.2)$ & $3(17.6)$ & $17(100)$ & \\
Total & $11(45.8)$ & $8(33.3)$ & $5(20.8)$ & $24(100)$ & \\
\hline
\end{tabular}

${ }^{1}$ Fisher's exact test of association reveals no significant association between gender and canine impaction side $(\mathrm{P}>0.05)$, indicating that in the study population, the distribution of the side of impaction is not associated with gender.

Table 5. Prevalence of unilateral and bilateral impacted canines.

\begin{tabular}{ccc}
\hline & $\mathrm{n}($ Prevalence \%) & P-value \\
\hline Unilateral & $19(1.4)$ & $0.004^{*}$ \\
Bilateral & $5(0.4)$ & \\
Total & $24(1.8)$ & \\
\hline
\end{tabular}

${ }^{1}$ Non-parametric chi-square test reveals significant $(\mathrm{P}<0.05)$ higher unilateral canine impaction compared to bilateral impaction. 
Another study in Turkey found that $3.27 \%$ of the investigated 2900 patients presented with impacted maxillary canines [8]. Camilleri [12], conducted a pilot study on 468 10-year old school children in Malta and reported the incidence of impacted maxillary canines. The study revealed that $4.4 \%$ was the prevalence. Maxillary canine impaction was found in 8 out of 568 participants $(4.71 \%)$ in a study on canine impaction in Croatia [10]. Furthermore, Gashi et al., [21] retrospectively investigated the records of 8101 Kosoviar patients treated in the University Dentistry Clinical Center of Kosovo, The result revealed that the incidence of maxillary canine impaction was (1.62\%). A study done in Saudi Arabia assessed the panoramic radiographs of 359 males found that 6 patients had at least one impacted maxillary canine which accounted for $1.67 \%$ of the studied population [22]. A prevalence of $1.36 \%$ was reported by Mustafa [18] who conducted a retrospective investigation on 3800 panoramic $\mathrm{x}$-rays of patients who had attended for treatment at the faculty of Dentistry at King Khaled University in Saudi Arabia. A study on the Panoramic x-rays of an Iraqi population involving 1050 cases revealed that the prevalence of maxillary canine impaction was $6.28 \%$ [17]. Hijjawi et al. [23] reported 36 cases out of 1368 cases to have at least one impacted maxillary canine with a prevalence rate of $2.14 \%$, the study sample was randomly selected from a population attending a private center specialized in dental radiography in Jenin district in Palestine. Watted et al., [24] examined the records of 2200 patients attending a private dental center in the city Jatt, in Palestine for treatment. Their study reported 82 (3.7\%) cases of at least one impacted maxillary canine among the study population. It is clear that the incidence of maxillary canine impaction varies with the population studied. The different results may be attributed to the racial differences and differences in the methodology of the study.

Prevalence of impacted maxillary canines among females was $3.1 \%$ and $0.9 \%$ among males. A significant association between gender and canine impaction $(\mathrm{P}<$ 0.05 ) is present, indicating that females have higher prevalence of canine impaction than males which is in agreement with other studies [12] [14] [16] [17] [19] [21]. The present study shows that cases with unilateral impacted maxillary canines (79\%) were significantly higher than those with bilateral impaction (19\%). These results are consistent with those obtained by other studies reporting that the majority of maxillary impactions occur unilaterally [10] [11] [13] [16]. Eleven cases had impacted canines on the right side of the maxillary arch, whereas 8 cases were on the left side. No significant $(\mathrm{P}>0.05)$ difference in the prevalence of right or left canine impaction. These findings were consistent with studies done in Turkey, Greece [8] [13]. Left side impactions were reported by other studies to be more common than right side impactions [11] [14] [23] [24]. Yet, other studies reported almost equal distribution of unilaterally impacted maxillary incisors between the left and right sides [10] [19]. The different results from these studies may arise from racial differences and differences in the methodology of the study including sample selection, definition of impacted tooth and the age of the individual. Clinical examination (visual inspection and palpation) and 
radiographic evaluation are recommended to inspect impacted maxillary canines when suspected [25]. Panoramic radiographs were used by the investigators who performed previous studies on the prevalence of impacted teeth [8]. Panoramic $\mathrm{x}$-rays only give a general overview, but do not permit precise localization of an impacted canine in three-dimensional space. The present study helps dental professionals learn more about the prevalence of impacted maxillary canines and promotes better understanding of the importance of early diagnosis and referral. If properly and timely done, an interdisciplinary treatment might prevent the patient from esthetic and functional discrepancies and can prevent many unwanted complications by only implementing preventive measures [7] [26].

Still, this study has limitations as the sample size was small and the sample population was only representative of the patient pool at a private clinic thus wider population groups should be studied in Palestine in order to draw.

\section{Conclusion}

The prevalence of maxillary canine impaction was $1.8 \%$ and was more commonly seen in females. The impaction occurred more unilaterally than in both sides. Unfortunately, the etiology of teeth impaction has never been investigated in the Palestinian population. Future studies are needed to evaluate the etiology of teeth impaction in Palestine.

\section{References}

[1] Sajnani, A.K. (2015) Permanent Maxillary Canines-Review of Eruption Pattern and Local Etiological Factors Leading to Impaction. Journal of Investigative and Clinical Dentistry, 6, 1-7. https://doi.org/10.1111/jicd.12067

[2] Bedoya, M.M. and Park, J.H. (2009) A Review of the Diagnosis and Management of Impacted Maxillary Canines. The Journal of the American Dental Association, 140, 1485-1493. https://doi.org/10.14219/jada.archive.2009.0099

[3] Park, J.H. and Tai, K. (2012) Impacted Maxillary Canines: Diagnosis and Management. Dent Today, 64-66.

[4] Becker, A. and Chaushu, S. (2015) Etiology of Maxillary Canine Impaction: A Review. American Journal of Orthodontics and Dentofacial Orthopedics, 148, 557567.

[5] Adina-Simona, C., Mariana, P. and Alina, O. (2013) Clinical and Statistical Study on Canine Impaction. Acta Medica Marisiensis, 59, 191-193. https://doi.org/10.2478/amma-2013-0044

[6] Bishara, S.E. (1992) Impacted Maxillary Canines: A Review. American Journal of Orthodontics and Dentofacial Orthopedics, 101, 159-171.

[7] Litsas, G. and Acar, A. (2011) A Review of Early Displaced Maxillary Canines: Etiology, Diagnosis and Interceptive Treatment. The Open Dentistry Journal, 5, 39-47. https://doi.org/10.2174/1874210601105010039

[8] Halıcıoğlu, K., Çörekçi, B. and Irgın, C. (2012) Incidence of Impacted Teeth and Transmigrated Canines-A Radiographic Study in Turkish Dental Patients. Clinical Research Dental, 36, 42-50.

[9] Chu, F.C.S., Li, T.K.L., Lui, V.K.B., Newsome, P.R.H., Chow, R.L.K. and Cheung, L.K. (2003) Prevalence of Impacted Teeth and Associated Pathologies-A Radio- 
graphic Study of the Hong Kong Chinese Population. Hong Kong Medical Journal, 9, 158-163.

[10] Prskalo, K., Zjaca, K., Skaric-Juric, T., Nikolic, I., Anic-Milosevic, S. and Lauc, T. (2008) The Prevalence of Lateral Incisor Hypodontia and Canine Impaction in Croatian Population. Collegium Antropologicum, 32, 1105-1109.

[11] Patil, S., Santosh, B., Khandelwal, S. and Maheshwari, S. (2014) Prevalence of Impacted Canines in Population of Western Part of India. Universal Research Journal of Dentistry, 4, 148. https://doi.org/10.4103/2249-9725.140672

[12] Camilleri, S. (1995) The Prevalence of Impacted Permanent Maxillary Canines in Maltese School Children: A Pilot Study. Malta Medical Journal, No. 1, 42-46.

[13] Fardi, A., Kondylidou-Sidira, A., Bachour, Z., Parisis, N. and Tsirlis, A. (2011) Incidence of Impacted and Supernumerary Teeth-A Radiographic Study in a North Greek Population. Medicina Oral, Patología Oral y Cirugía Bucal, 16, e56-e61. https://doi.org/10.4317/medoral.16.e56

[14] Kifayatullah, J., Bangash, T., Ayub, A. and Khan, D. (2015) Prevalence and Patterns of Impacted Maxillary Canine. Pakistan Oral and Dental Journal, 35, 57-61.

[15] Alif, S.M., Haque, S., Nimmi, N., Ashraf, A., Khan, S.H. and Khan, M.H. (2011) Panoramic Radiological Study to Identify Locally Displaced Maxillary Canines in Bangladeshi Population. Imaging Science in Dentistry, 41, 155-159. https://doi.org/10.5624/isd.2011.41.4.155

[16] Sharmila, R. (2016) Incidence of Impacted Canine Using Orthopantomogram. Pharmaceutical Sciences and Research, 8, 921-922.

[17] Saeed, O., Fatehulla, K. and Abdulateef, D. (2015) Prevalence of Canine Impaction in a Selected Sample of Sulaimani City Population. International Journal of Developmental Neuroscience, 5, 5816-5819.

[18] Mustafa, A. (2014) Prevalence of Impacted Canine Teeth in College of Dentistry, King Khalid University-A Retrospective Study. International Journal of Health Sciences and Research, 4, 211-214.

[19] Sajnani, A.K. and King, N.M. (2014) Prevalence and Characteristics of Impacted Maxillary Canines in Southern Chinese Children and Adolescents. Journal of Investigative and Clinical Dentistry, 5, 38-44. https://doi.org/10.1111/jicd.12027

[20] Sandeepa, N., Ajmal, M. and Deepika, N. (2016) A Retrospective Panoramic Radiographic Study on Prevalence of Pulp Stones in South Karnataka Population. World Journal of Dentistry, 7, 14-17. https://doi.org/10.5005/jp-journals-10015-1356

[21] Gashi, A., Kamberi, B., Ademi-Abdyli, R., Perjuci, F. and Sahatçiu-Gashi, A. (2014) The Incidence of Impacted Maxillary Canines in a Kosovar Population. International Scholarly Research Notices, 2014, Article ID: 370531. https://doi.org/10.1155/2014/370531

[22] El-Khateeb, S.M., Arnout, E.A. and Hifnawy, T. (2015) Radiographic Assessment of Impacted Teeth and Associated Pathosis Prevalence: Pattern of Occurrence at Different Ages in Saudi Male in Western Saudi Arabia. Saudi Medical Journal, 36, 973979. https://doi.org/10.15537/smj.2015.8.12204

[23] Hijawi, S.I., Hussein, A.M. and Mohammad, Z.K.M. (2016) Prevalence of Impacted and Transmigrated Canine among Palestinian People-Jenin District. Journal of Basic and Applied Research International, 2, 272-276.

[24] Watted, N., Abu-hussein, M., Awadi, O., Watted, M., Watted, A.L. and Watted, A. (2014) Incidence of Canine Impaction in Palestinian Population. Journal of Advanced Oral Research, 5, 4-10.

[25] Manne, R., Gandikota, C., Juvvadi, S.R., Rama, H.R.M. and Anche, S. (2012) Im- 
pacted Canines: Etiology, Diagnosis, and Orthodontic Management. Journal of Pharmacy and Bioallied Sciences, 4, S234-S238.

[26] Mirabella, D., Giunta, G. and Lombardo, L. (2013) Substitution of Impacted Canines by Maxillary First Premolars: A Valid Alternative to Traditional Orthodontic Treatment. American Journal of Orthodontics and Dentofacial Orthopedics, 143, 125-133.

\section{Scientific Research Publishing}

Submit or recommend next manuscript to SCIRP and we will provide best service for you:

Accepting pre-submission inquiries through Email, Facebook, LinkedIn, Twitter, etc. A wide selection of journals (inclusive of 9 subjects, more than 200 journals)

Providing 24-hour high-quality service

User-friendly online submission system

Fair and swift peer-review system

Efficient typesetting and proofreading procedure

Display of the result of downloads and visits, as well as the number of cited articles Maximum dissemination of your research work

Submit your manuscript at: http://papersubmission.scirp.org/

Or contact ojst@scirp.org 